560 benign breast lumps--Lingnan Modern Clinics in Surger $2007 \quad<$ http://en.cnki.com. cn/Article_en/CJFDTOTAL-LNWK

200705013.htm>, accessed: 04/06/2018.
9. Li S., Wu J., Chen K. và cộng sự. (2013). Clinical outcomes of 1,578 Chinese patients with breast benign diseases after ultrasound-guided vacuum-assisted excision: recurrence and the risk factors. Am J Surg, 205(1), 39-44.

\title{
ĐÁNH GIÁ KẾT QUẢ SAU THÁO DẦU SILICON NộI NHÃN TRÊN MẮT ĐÃ PHẪU THUÂTT VIÊM MỦ NộI NHÃN DO VẾT THƯƠ'NG XUYÊN NHÃN CẦU
}

\author{
Phan Thị Thu Hương*, Thẩm Trương Khánh Vân*, \\ Nguyễn Thị Thu Hiền*, Nguyễn Thị Thu Yên*
}

\section{TÓM TẮT}

Mục tiêu: Đánh giá kết quả sau tháo dầu silicon nôi nhã̃n trên mắt đã phẫu thuât viêm mủ nội nhãn do vết thương xuyên nhãn cầu. Đối tượng và phương pháp nghiên cứu: Nghiên cứu mô tả, tiến cứu không đối chứng trên 30 mắt của 30 bệnh nhân đã được tháo dâu silicon sau mổ cắt dich kính điều trị viêm mủ nội nhãn do vết thương xuyên nhãn câu có bơm dâu silicon nội nhãn, tại khoa Chấn thương mắt bệnh viện Mắt Trung Ương. Kết quả: Về chức năng: thị lực cải thiện là 73,33\%, có sự khác biệt rõ ràng giữa thị lực saư phấu thuật và thị lực lúc vào viện; nhãn áp sau phẫu thuật: phần lớn ở mức bình thường $90 \%$, có $3,33 \%$ nhãn áp cao và $6,67 \%$ nhãn áp thấp do biến chứng bong võng mạc. Về mặt giải phâuu: 36,67\% các mắt sạch dâuu buông dịch kính và $56,67 \%$ là còn bóng dầu nhỏ; võng mạc áp chiếm $90 \%$ số mắt. Kết luận: Tháo dâu silicon nội nhãn đem lại hiệu quả cải thiên rõ rệt về mặt chức năng và giải phẫu cho các mắt đã được điều trị viêm mủ nôi nhãn do vết thương xuyên nhẳn cầu đã được cắt dịch kính mủ kèm ân độn nội nhãn bằng dầu silicon nhãn

Từ khóa: tháo dầu silicon nội nhãn, viêm mủ nội

\section{SUMMARY \\ OUTCOMES AFTER SILICONE OIL \\ REMOVAL IN ENDOPHTHALMITIS DUE OCULAR PENETRATING INJURIES}

Objectives: To evaluate the outcomes after Silicone oil removal in endophthalmitis due to ocular penetrating injuries. Subjects and methods: Descriptive, prospective, uncontrolled study on 30 eyes of 30 patients who had silicone oil removed after vitrectomy to treat endophthalmitis due to transocular trauma with oil pump. Intraocular silicone, at the Department of Eye Trauma, Central Eye Hospital. Result: In terms of function: improved visual acuity is $73.33 \%$, there is a clear difference between visual acuity after surgery and visual acuity at hospital

*Bệnh viện Mắt Trung ương

Chiu trách nhiẹm chính: Phan Thị Thu Hương

Email: dr.huongphan@gmail.com

Ngày nhận bài: 10.3.2021

Ngày phản biện khoa học: 29.4.2021

Ngày duyệt bài: 11.5.2021 admission; IOP after surgery: most of them are in $90 \%$ normal range, there are $3.33 \%$ high IOP and $6.67 \%$ low IOP due to retinal detachment complications. Anatomically: $36.67 \%$ of the eyes were clear of vitreous oil and $56.67 \%$ had small oil balls; Pressure retina accounts for $90 \%$ of the eyes. Conclusion: Removal of intraocular silicone oil brought a significant improvement in function and anatomy for the eyes treated with endophthalmitis due to the trans-ocular wound that had been removed with purulent vitreous and intraocular pressure. silicone oil label.

Key Words: Silicone oil removal, silicone oil, endophthalmitis

\section{I. ĐẶT VẤN ĐỀ}

Phẫu thuật cắt dịch kính (CDK) kèm bơm dầu silicon nôi nhãn là phương pháp hữu ích được áp dụng để điều trị viêm mủ nội nhãn (VMNN) do vết thương xuyên nhãn cầu (VTXNC) nhằm loại bỏ và hạn chế sư phát triển của tác nhân gây bênh và độc tố, đồng thời giúp võng mac không bị bong, giúp thuốc kháng sinh - chống viêm khuyếch tán tốt hơn, chống hạ nhãn áp. Tưy nhiên, dầu silicon không thể lưu lại vĩnh viễn trong mắt. Sau một thời gian (khoảng từ 2 tháng) dầu silicon có thể nhuyễn hóa gây nên các biến chứng cho các mô nội nhãn như võng mac, thể thủy tinh, giác mac.... Do đó, sau khi đã đạt được hiệu quả điều trị, dầu silicon cần được lấy khỏi mắt sớm. Vậy sau khi tháo dầu silicon nội nhãn, liệu tình trạng giải phẫu cũng như chức năng thi giác của mắt có được cải thiên? Chúng tôi đã tiến hành nghiên cứu "Đánh giá kêt quả sau tháo dầu silicon nội nhãn trên mắt đã phẫu thuật viêm mủ nội nhãn do vết thương xuyên nhã̃n cầu" nhằm mục tiêu: Đánh giá kết quả sau tháo dầu silicon nội nhãn trên mắt đã phẫu thuật viêm mủ nội nhãn do vêt thương xuyên nhãn cầu.

\section{II. ĐỐI TƯỢNG VÀ PHƯƠNG PHÁP NGHIÊN CỨU \\ 2.1. Đối tượng nghiên cứu \\ 2.1.1. Đối tượng nghiên cứu: Nghiên cứu}


được tiến hành trên 30 mắt (30 bệnh nhân) được tháo dầu silicon sau mổ CDK điều trị VMNN do VTXNC có bơm dầu silicon nội nhãn, tại khoa Chấn thương mắt bệnh viện Mắt Trung Ương từ tháng 12/2014 đến tháng 12/2015.

2.1.2. Tiêu chuẩn lựa chọn bệnh nhân: Là các bệnh nhân đã được phẫu thuật CDK - bơm dâu silicon nội nhãn điêu trị VMNN do VTXNC và có chỉ định tháo dầu khi: mắt hết viêm, hết nhiễm trùng $g_{\ell}$ võng mạc áp tốt các hướng, dầu đã nhuyến hóa, hoặc chưa có dầu nhuyễn hóa nhưng có những biến chứng không thể khống chế của dâuu (tăng nhãn áp không điều trị được bằng thuốc, loạn dưỡng giác mạc...).

Bệnh nhân đồng ý tham gia nghiên cứu.

2.1.3. Tiêu chuẩn loại trừ: chúng tôi loại trừ khỏi nghiên cứu các bệnh nhân có: 1 . Mắt đã mất chức năng; 2 . Bệnh nhân quá già yếu, hoặc trẻ quá nhỏ ( $<5$ tuổi) do khó có điều kiện thăm khám và theo dõi.

\subsection{Phương pháp nghiên cứu}

2.2.1. Thiết kế nghiên cứu: là nghiên cứu mô tả, tiến cứu không đối chứng.

2.2.3. Cách chọn mẫu: Chọn liên tục các bệnh nhân bị VMNN do VTXNC đã được phẫu thuật CDK có bơm dầu silicon nội nhãn đáp ứng được các tiêu chuẩn lựa chọn vào nghiên cứu.

2.2.4. Tiến hành nghiên cứu: Các bệnh nhân đáp ứng tiêu chuẩn nghiên cứu được phẫu thuật tháo dầu silicon nội nhãn. Bệnh nhân xuất viện được hẹn khám lại sau 1 tuần, 1 tháng, 3 tháng và đánh giá các chỉ tiêu đã được đặt ra trong nghiên cứu.

\subsection{Các tiêu chí đánh giá bao gồm}

2.3.1. Đặc điểm nhóm nghiên cứu bao gồm: Tuổi, giới tính, thị lực, nhãn áp , tình trạng võng mạc: võng mạc có tắng sinh dịch kính võnng mạc hay không có tăng sinh dịch kính võng mạc, thời gian lưu dâu trong mắt.

\subsection{2. Đánh giá kết quả phẫu thuật}

\subsubsection{Kết quả chức năng}

+ Thị lực: thị lực được cho là cải thiện sau phẫu thuật khi bệnh nhân có thị lực ban đầu $\geq$ 20/200 thì phải nhìn tăng thêm từ 2 hàng trở lên. Đối với bệnh nhân thị lực ban đầu từ ĐNT $1 \mathrm{~m}$ đến $<20 / 200$ thị lực tăng từ ĐNT $1 \mathrm{~m}$ trở lên thì có ý nghĩa. Với những bệnh nhân thị lực ban đầu < ĐNT $1 \mathrm{~m}$ thì bất kỳ sự tăng lên về thị lực đều được coi là cải thiện.

+ Tình trạng nhãn áp sau phẫu thuật: Nhãn áp thấp $(\leq 15 \mathrm{mmHg})$, nhãn áp bình thường (từ $15-\leq 24 \mathrm{mmHg}$ ), nhãn áp cao (>24mmHg).

\subsubsection{Kết quả giải phâu}

+ Tình trạng võng mạc: áp hay bong võng mạc (BVM) sau tháo dầu, nễu võng mạc áp thì có tăng sinh dịch kính võng mạc hay không có tăng sinh dịch kính võng mạc.

+ Tình trạng buồng dịch kính (BDK) được chia làm 3 mức độ: 1 . Sạch dầu: khám buồng dịch kính sạch, khổng còn các bọt dầu nhỏ li ti trong buồng dịch kính, siêu âm rõ không bị cản sóng siêu âm; 2. Còn hạt dầu nhỏ: những giọt dầu rất nhỏ lơ lửng buồng dịch kính, kích thước $\approx 1-3 \mu \mathrm{m}$, quan sát rõ trên siêu âm, cản sóng siêu âm ít; 3. Bóng dầu to: những giọt dầu to quan sát bằng sinh hiển vi được.

\section{KẾT QUẢ NGHIÊN CỨU}

3.1. Đặc điểm nhóm bệnh nhân nghiên cứu

3.1.1. Phân bố bệnh nhân theo tuổi và giới: Bệnh VMNN do VTTX phải phẫu thuật CDK phối hợp bơm dâuu silicon nội nhãn trong nghiên cứu gặp ở tất cả các lứa tuổi, tuy nhiên lứa tuổi hay gặp nhất là tuổi từ 20 đến 40 chiếm $53,33 \%$. Độ tuổi trung bình mắc bệnh là 30,80 \pm 15,16 , thấp nhất là 6 tuổi và cao nhất là 61 tuổi. Cũng trong nghiên cứu này chúng tôi thây tỷ lệ nam/ nữ là 73,33\% / 26,67\%, nam giới chiếm tỷ lệ chủ yếu.

3.1.2. Phân bố bệnh nhân theo tình trạng thị lực vào viện: Đa phần bệnh nhân đến viện với mức thị lực rất thấp (73,33\% có thị lực từ ST (+) đến ĐNT $1 \mathrm{~m}$ ). Mức thị lực trong khoảng từ ĐNT $1 \mathrm{~m}$ đến ĐNT $<3 \mathrm{~m}$ và từ ĐNT $3 \mathrm{~m}$ đến < 20/200 chiếm cùng tỷ lệ $13,33 \%$, không có bệnh nhân nào vào viện với thị lực > 20/200.

3.1.3. Phân bố bệnh nhân theo tình trạng nhãn áp vào viện: Phần lớn nhãn áp vào viện của các bệnh nhân nằm trong giới hạn bình thường $(80 \%)$, có $6 / 30(20 \%)$ bệnh nhẩn có nhãn áp cao và không có bệnh nhân nào có nhãn áp thấp.

3.1.4. Thời gian lưu dâu trong mắt: Đa phần bệnh nhân trong nhóm nghiên cứu có thời gian lưu dầu trong mắt $>6$ tháng $(50 \%)$ và từ 3 đến 6 tháng $(46,67 \%)$, chỉ có $1 / 30(3,33 \%)$ mắt có thời gian lưu dầu dưới 3 tháng. Thời gian lưu dầu trung bình là $10,10 \pm 8,88$ tháng, thời gian Iưu dâu thấp nhất là 2 tháng, cao nhất là 37 tháng.

3.1.5. Tình trạng võng mạc: Trong số 30 bệnh nhân nghiên cứu thì có 24 bệnh nhân kiểm tra được tình trạng võng mạc trước phấu thuật (trong đó: $73,33 \%$ bệnh nhân không có tăng sinh dịch kính võng mạc, chỉ có $6,67 \%$ bệnh nhân có tình trạng tăng sinh dịch kính võng mạc) và 6 bệnh nhân không kiểm tra được tình trạng võng mạc trước phẫu thuật do thoái hóa giác mạc dải băng, giác mạc phù bọng nhiều kèm loạn dưỡng 
giác mạc do tăng nhãn áp kéo dài, dầu nhuyễn hóa ra tiền phòng che lấp diện đồng tử...

\subsection{Kêt quả sau phẫu thuật}

3.2.1. Kết quả chức năng

3.2.1.1. Kết quả thị lực tại các thời điểm dõi: Không có sự khác biệt về mức độ cải thiện thị lực tại thời điểm vào viện và ra viện. Thị lực bắt đầu có sự cải thiện tại thời điểm theo dõi sau 1 tuần và dần ổn định tại các thời điểm theo dõi sau đó 1 tháng và 3 tháng. Tại thời điểm ra viện thị lực nằm trong khoảng từ $\mathrm{ST}(+)$ đến $\mathrm{DNT} 1$ $m$ chiếm tỷ lệ cao nhất $80 \%$, thị lực nằm trong khoảng ĐNT 1m đến ĐNT < 3m chiếm tỷ lê 10\% và từ ĐNT $3 m$ đến < 20/200 chiểm tỷ lệ $6,67 \%$. Mức thị lực từ 20/200 đến 20/60 là 3,33\%, không có trường hợp nào có thị lực $\geq 20 / 60$.Tại thời điểm theo dõi sau 3 tháng phần lớn thị lực nằm trong khoảng ĐNT $3 m$ đến < 20/200 chiếm tỷ lệ $30 \%$, có 6 trường hợp thị lực nằm trong khoảng 20/200 đến < 20/60 (20\%) và 1 trường hợp thị lực > 20/60 (3,33\%). Thị lực lúc mới vào viện và thị lực sau theo dõi 3 tháng có sự khác biệt rõ rệt, có ý nghĩa thống kê với $p<0,001$.

3.2.1.2. Kêt quả cải thiện thị lực sau phẫu thuật

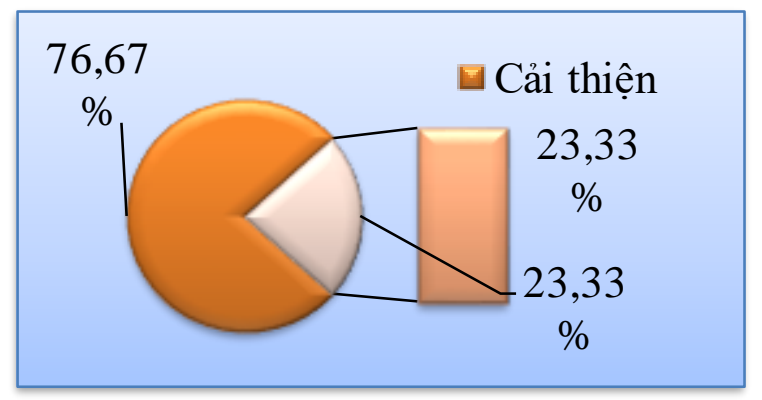

Biểu đồ 3.1. Kêt quả cải thiện thị lực sau phẫu thuật
Sau phẫu thuật có $76,67 \%$ bênh nhân có thi lực cải thiện. Chỉ có $23,33 \%$ bệnh nhân có thị lực không cải thiện so với khi vào viện (do biến chứng trong phẫu thuật, do teo nhãn cầu, do teo thị thần kinh và do BVM tái phát).

3.2.1.3. Kết quả nhãn áp tại các thời điểm theo dõi sau phẫu thuật: Phần lớn nhãn áp tại các thời điểm theo dõi đều ở mức bình thường. Sau theo dõi 3 tháng có $2 / 30(6,67 \%)$ bị nhãn áp thấp và $1 / 30(3,33 \%)$ bị nhãn áp cao do còn các bọt dâu liti kẹt vào vùng bè gây bít tắc trong thoát thủy dich.

\subsubsection{Kết quả giải phẫu}

3.2.2.1. Tình trạng buồng dịch kính sau phẫu thuật

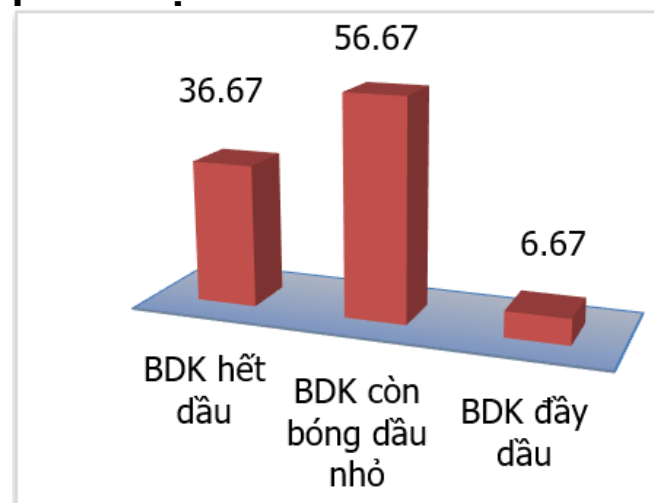

\section{Biểu đồ 3.2. Tình trạng buồng dịch kính sau phẫu thuât}

Sau phẫu thuật phần lớn bệnh nhân vẫn còn bọt dầu nhỏ liti trong buồng dịch kính chiếm tỷ lệ $56,67 \%$, chỉ có $36,67 \%$ dâu được tháo hết ra khỏi buồng dịch kính. Có 2 trường hợp phải bơm lại dầu luôn tại thời điểm phẫu thuật do bong võng mạc tái phát ngay trên bàn mổ.

\subsubsection{Tình trạng võng mạc tại các thời điểm theo dõi sau phẫu thuật}

Bảng 3.4. Tình trạng vông mạc tại các thời điểm theo dôi

\begin{tabular}{|c|c|c|c|c|c|c|c|c|c|c|c|}
\hline \multirow{2}{*}{\multicolumn{2}{|c|}{$\begin{array}{l}\text { Thời gian } \\
\text { Võng mạc }\end{array}$}} & \multicolumn{2}{|c|}{ Vào viện } & \multicolumn{2}{|c|}{ Ra viện } & \multicolumn{2}{|c|}{ Sau 1 tuân } & \multicolumn{2}{|c|}{ Sau 1 tháng } & \multicolumn{2}{|c|}{ Sau 3 tháng } \\
\hline & & $\mathbf{n}$ & $\%$ & $\mathbf{n}$ & $\%$ & $n$ & $\%$ & $\mathbf{n}$ & $\%$ & $\mathbf{n}$ & $\%$ \\
\hline \multirow{2}{*}{ Áp } & $\begin{array}{l}\text { Không } \\
\text { TSDKVM }\end{array}$ & 22 & 73,33 & 26 & 86,67 & 25 & 83,33 & 23 & 76,67 & 21 & 70 \\
\hline & TSDKVM & 2 & 6,67 & 4 & 13 & 4 & 13 & 6 & 20 & 6 & 20 \\
\hline & Tổng & 24 & 80 & 30 & 100 & 29 & 96,67 & 29 & 96,67 & 27 & 90 \\
\hline \multicolumn{2}{|c|}{ Bong võng mac } & 0 & 0 & 0 & 0 & 1 & 3,33 & 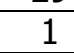 & 3,33 & 3 & 10 \\
\hline \multicolumn{2}{|c|}{ Không soi được } & 6 & 20 & 0 & 0 & 0 & 0 & 0 & 0 & 0 & 0 \\
\hline \multicolumn{2}{|c|}{ Tổng số } & 30 & 100 & 30 & 100 & 30 & 100 & 30 & 100 & 30 & 100 \\
\hline
\end{tabular}

Phần lớn tại các thời điểm sau ra viện khám lâm sàng đáy mắt bằng sinh hiển vi và bằng siêu âm cho thấy võng mạc áp chiếm tỷ lệ lớn hơn $90 \%$. Trong đó võng mạc áp không có tăng sinh dịch kính võng mạc (70\%) có tỷ lệ cao hơn võng mạc áp có tăng sinh dịch kính võng mạc (20\%). Sau 3 tháng theo dõi chúng tôi thấy có $3 / 30(10 \%)$ bị bong võng mạc tái phát. 


\section{BÀN LUÂN}

4.1. Đặc điểm bênh nhân nghiên cứu: Cũng tương tự như các nghiên cứu khác về chấn thương mắt, bệnh nhân trong nhóm nghiên cứu của chúng tôi cũng thường gặp ở lứa tuổi trẻ, nam giới chiếm đa số $(73,33 \%)$ với độ tuối trung bình là $30,80 \pm 15,16$; Kết quả này tương tự như kết quả nghiên cứu trên 30 mắt bị chấn thương xuyên nghiêm trọng có và không có dị vật nội nhãn của Ahmed M. (2015) [3]. Điêu này có thể là do nam giới là lực lượng lao động chính, thường tiếp xúc với cổng việc nặng nhọc và nguy hiểm như gò hàn, đóng đinh, chặt sắt, đập đá,... nên chấn thương thường gặp nhiều hơn.

4.2. Thị lực và nhãn áp vào viện: Thị lực trước phẫu thuật đã từ lâu được coi là một yếu tố tiên lượng quan trong đối với kết quả chức năng. Thị lực vào viện của nhóm nghiên cứu tương đối thấp vì võng mạc đã bị tổn hại trầm trọng do chấn thương và viêm mủ nội nhãn đi kèm đó là các các tổn thương phối hợp khác do chấn thương gây ra. Tại thời điểm vào viện, có tới 73,33\% thị lực ở khoảng ST (+) đến ĐNT $1 \mathrm{~m}$ và không có mắt nào đạt thị lực $>20 / 200$.

Nhãn áp vào viện phần lớn là nhãn áp bình thường, chỉ có $16,67 \%$ nhãn áp cao do biến chứng của dâu silicon nội nhãn. Kết quả này tương tự kết quả nghiên cứu của Ahmed M.A.H.(2015) [6] khi đánh giá tỷ lệ bong võng mạc tái phát sau tháo dâu là một trong những nguyên nhân để tác giả quyết định tháo dầu silicon nội nhãn sớm.

4.3. Thời gian lưu dâu trong mắt: Nghiên cứu của chúng tôi có thời gian lưu dầu trung bình là $10,10 \pm 8,88$ tháng dao động từ 2 đến 37 tháng. Kết quả này gần tương tự với kết quả nghiên cứu của Christiane IF. (2001) [4] với thời gian lưu dầu trung bình là 13,3 tháng. Tuy nhiên, nghiên cứu của Ahmed M.A.H (2015) [3] lại có thời gian lưu dầu trung bình là $5,26 \pm 1,05$ tháng. Thời gian tháo dầu ra khỏi nội nhãn thì không có một quy định cụ thể nào mà tùy thuộc vào từng bềnh nhân. Theo đa số tác giả thì chỉ nên lưu dầu từ 3 đến 6 tháng [5]. Bệnh nhân đựoc chỉ định tháo dầu khi vai trò của dầu đã hoàn tất (hết phản ứng viêm, lành sẹo, võng mạc áp, ...) và khi xảy ra các biến chứng do dầu (như tăng nhãn áp, dâu ra tiền phòng, thoái hóa giác mạc dải băng, ...), khi dầu đã bị biến chất gây hiện tượng nhuyễn hóa.

\subsection{Kết quả sau phẫu thuật}

4.3.1. Kết quả chức năng

4.3.1.1. Thị lực: Trong nghiên cứu của chúng tôi, thị lực tăng dần theo thời gian, không có bệnh nhân nào mất thị lực hoàn toàn. Thị lực ra viện của các bệnh nhân vần còn kém là do còn phản ứng viêm sau mổ, còn bóng khí nội nhãn, do kích thích từ mép mổ... Theo thời gian, các phản ứng viêm sau phẫu thuật hết, bóng khí tiêu hết, không còn kích thích từ mép mổ làm cho thị lực của bệnh nhân tăng dần. Kết quả nghiên cứu của chúng tôi cũng gần tương tự kết quả nghiên cứu của tác giả Scholda và cộng sự (1997) [5] với thị lực > 20/200 chiểm tỷ lệ 48,2\%, thị lực < $20 / 200$ chiếm tỷ lệ $51,8 \%$ sau mố. Tương tự như vậy khi đánh giá sự cải thiện về thị lực, nghiên cứu của Yan $\mathrm{H}$ và cộng sự (2008) về ứng dụng của dầu silicon trong việc điều trị phẫu thuật các ca viêm mủ nội nhãn do chấn thương cũng cho thây [7], thị lực được cải thiện ở 15 mắt (83\%) và không đổi ở 3 mắt (17\%).

4.3.1.2. Nhãn áp: Tai tất cả các thời điểm nghiên cứu, tuyệt đại đa số các trường hợp (>90\%) nhãn áp trong giới hạn bình thường. Tại cuối thời điểm theo dõi có $2 / 30(6,67 \%)$ có nhãn áp thấp do bong hắc võng mạc và bong võng mạc gần toàn bộ, 2 trường hợp nhãn áp cao đã điều chỉnh được bằng thuốc, không bệnh nhân nào cần phải can thiệp phẫu thuật. Kết quả nghiên cứu này của chúng tôi gần tương tự với kết quả của nhiều nghiên cứu tháo dầu silicon nội nhãn khác [3],[4],[6]. Nghiên cứu của Schoda $C$ và cộng sự [5] khi đánh giá kết quả sau tháo dầu silicon trên các mắt bong võng mạc lại cho thấy tỷ lệ tăng nhãn áp sau mổ tương đối cao $27,7 \%$ với 5 mắt cần phải can thiệp phẫu thuật hạ nhãn áp. Tuy nhiên, ngay trước tháo dầu, tỷ lệ tăng nhãn áp của tác giả cũng cao hơn chúng tôi là $33,7 \%$ so với $20 \%(16,7 \%)$.

\subsubsection{Kết quả giải phẫu}

4.3.2.1. Tình trạng buồng dịch kính: Khi dầu nhuyễn hóa, các bọt dầu nhỏ liti len sâu vào các khe rãnh mống mắt, thể mi và dịch kính chu biên. Chính vì vậy, khi tháo dầu việc để hút sạch hoàn toàn các bọt dâu liti này khá khó khăn, mà trong nhóm nghiên cứu trên 30 mắt của chúng tôi có $83,33 \%$ mắt có hiện tượng dầu nhuyễn hóa. Mặc dù chúng tôi đã tiến hành trao đổi khí dịch nhiều lần nhưng vẫn khó tránh khỏi hiện tượng sót những giọt dầu nhỏ li ti ở một số trường hợp. Sau tháo dầu tỷ lệ các bot dâu nhỏ liti trong buồng dịch kính của chúng tôi là $56,67 \%$. Trong khi đó kết quả nghiên cứu của tác giả Ứng Xuân Hiếu (2011) [2] về đánh giá kết quả tháo dầu sau phẩu thuật bong võng mạc ở 32 mắt cho thấy: trước phẫu thuật có $68,6 \%$ mắt có dầu nhuyễn hóa, sau phẫu thuật dầu silicon không thể tháo sạch hoàn toàn khỏi 
buồng dịch kính, có tới 97,4\% còn những bọt dầu nhỏ liti trong BDK.

4.3.2.2. Đánh giá kết quả võng mạc: Nghiên cứu của chúng tôi cho thây tại tất cả các thời điểm theo dõi võng mạc áp chiếm tỷ lệ tương đối cao $\geq 90 \%$. Kêt quả của chúng tôi cao hơn so với kết quả sau tháo dầu silicon nội nhãn của Đặng Trần Đạt (2002) [1] với tỷ lệ võng mạc áp sau tháo dầu là 77,78 và của Ahmed M.A.H. Chúng tôi cho rằng, kết quả của chúng tôi tốt hơn của 2 tác giả trên là do đối tượng của chúng tôi là các bệnh nhân VMNN sau VTXNC. Ở các bệnh nhân này, tăng sinh dịch kính võng mạc không tồn tại trước phẫu thuật và việc tháo dẩu chỉ được thực hiện khi quá trình viểm nhiếm yếu tố nguy cơ gầy tăng sinh dịch kính võng mạc đã được khống chế trong khi đó đối tượng nghiên cứu của các tác giả trên là các bệnh nhân đã có tăng sinh dịch kính võng mạc, rách khổng lồ, chấn thương mắt nặng... là các yếu tố hàng đâu gây tăng sinh dịch kính võng mạc.

\section{KẾT LUÂ̂N}

Qua phân tích các số liệu và kết quả nghiên cứu trên 30 mắt của 30 bệnh nhân, chúng tôi thây có sự cải thiện rõ rệt về chức năng và giải phẫu sau khi tháo dầu silicon đối với bệnh nhân có mắt bị viêm mủ nội nhãn do vết thương xuyên nhãn cầu đã được phẫu thuật cắt dịch kính mủ có bơm ấn độn silicon nội nhẳn.

\section{TÀI LIÊU THAM KHẢO}

1. Đặng Trân Đạt (2002). Nghiên cứu sử dung dâu silicon trong phẫu thuật điểu trị một số hình thái bong võng mạc, Luân văn tốt nghiệp Bác sỹ nội trú bệnh viện, Đại học Ỳ Hà Nôi.

2. Ứng Xuân Hiếự, Cung Hồng Sơn(2011). Đánh giá kết quả phâuu thuật tháo dầu silicon trên mắt đã mổ bong võng mạc, Luận văn thạc sỹ y học, Đại học Y Hà Nội.

3. Ahmed M. Abdel Hadi (2015). Incidence of retinal redetachment after silicon oil removal in cases of severe eye injuries operated during the 25th of January Egyptian Revolution. Journal of Egyptian Ophthalmological Society, 108, 115-120.

4. Christiane I Falkner et al (2001). Outcome after silicon oil removal. Br J Ophthalmol;85, 1324-1327.

5. Scholda C et al (1997). Silicon oil removal results, risks and complications. Acta Ophthalmol Scand; 75, 695-699.

6. Shakir Zafar et al (2013). Outcomes of Silicon Oil Removal. Journal of the College of Physicians and Surgeons Pakistan, 23(7), 476-479.

7. Yan, H. Lu, Y. et al (2008). Silicon oil in the surgical treatment of traumatic endophthalmitis. Eur J Ophthalmol, 18 (5), 680-684.

\section{TÁC DỤNG Đİ̀̃U CHİNH RỐI LOẠN LIPID MÁU CỦA VIÊN NANG LINH QUẾ TRUÂT CAM - NHI TRẦN THANG GIA VI! TRÊN CHUộT CỐNG TRẮNG}

\section{TÓM TẮT}

Mục tiêu: Đánh giá tác dụng điều chỉnh rối loạn lipid máu của viên nang Linh quế truật cam thang Nhị trần thang gia giảm (LQTCT-NTT) trên chuột cống trắng rối loạn lipid máu ngoại sinh. Phương pháp: Chuột cống trắng được gây rối loạn lipid máu bằng cách cho uống hốn hợp dâuu cholesterol, sau đó 2 giờ được cho uống thuốc nghiên cứu, liên tục trong 28 ngày. Đánh giá các chỉ số lipid máu, hình ảnh đại thể, vi thể gan chuột. Kết quả: LQTCT-NTT liều $0,28 \mathrm{~g} / \mathrm{kg} / \mathrm{ngày}$ và $0,56 \mathrm{~g} / \mathrm{kg} / \mathrm{ngày}$ làm giảm các chỉ số lipid máu gôm Triglyceride, cholesterol TP, LDL-

1,2,3Học viện Y Dược học Cổ truyền Việt Nam

${ }^{4}$ Học viện Quân $Y$

Chịu trách nhiệm chính: Tôn Mạnh Cường

Email: bacsytonmanhcuong@gmail.com

Ngày nhận bài: 11.3.2021

Ngày phản biên khoa học: 29.4.2021

Ngày duyệt bài: 12.5.2021

Tôn Mạnh Cường1, Trương Việt Bình ${ }^{2}$, Nguyễn Tuấn Bình ${ }^{3}$, Nguyễn Thanh Hà Tuấn ${ }^{4}$

Cholesterol, VLDL- Cholesterol; giảm chỉ số Atherogenic; tăng HDL-Cholesterol máu; giảm mõ bụng, giảm tình trạng nhiễm mõ̃ gan. Các tác dụng này của LQTCT-NTT' tương đương với Atorvastatin liều $10 \mathrm{mg} / \mathrm{kg} / \mathrm{ngày}$. Kết luânn: Viên nang LQTCT-NTT có tác dụng tốt trong điều chỉnh rối loạn lipid máu ngoại sinh trên chuột cống trắng.

Tư khóa: LQTCT-NTT, rối loạn lipid máu, cơ chế ngoại sinh, chuột cống trắng.

\section{SUMMARY}

\section{EFFECTS OF DYSLIPIDEMIA REGULATING \\ OF LINH QUE TRUAT CAM NHI TRAN CAPSULES ON WHITE RATS}

Objective: To evaluate the effect of regulating dyslipidemia of the LQTCT-NTT capsule on exogenous dyslipidemia rats. Methods: Wistar rats were induced dyslipidemia by drinking a mixture of cholesterol oil, 2 hours later were given the experimental drugs, continuously for 28 days. Evaluation of blood lipid indexes, macroscopic and microscopic images of liver. 